\title{
Management of post-tuberculous complex aspergilloma of the lung: role of surgical resection
}

\author{
Sulaiman A Al-Majed, Mahmoud Ashour, Feisal A El-Kassimi, Ismail Joharjy, \\ Abdullah Al-Wazzan, Mohamad S Al-Hajjaj, Rajagopalen Vijay
}

Department of
Medicine
S A Al-Majed
F A El-Kassimi
A Al-Wazzan
M S Al-Hajiaj
Department of
Surgery
M Ashour
R Vijay
Department of
Radiology
I Johariy
College of Medicine,
King Saud University,
Riyadh, Saudi Arabia
Address for reprint requests:
Dr Sulaiman A Al-Majed,
Medical Department,
College of Medicine, King
Saud University, PO Box
2925, Riyadh 11461, Saudi
Arabia.
Accepted 14 August 1990

Department of

$S$ A Al-Majed

F A El-Kassim

M S Al-Hajiaj

Department of

M Ashou

Radiology

I Joharjy

Riyadh, Saudi Arabia

Address for reprint requests: Dr Sulaiman A Al-Majed,

College of Medicine, Kin

Saud University, PO Box

Arabia.

Accepted 14 August 1990

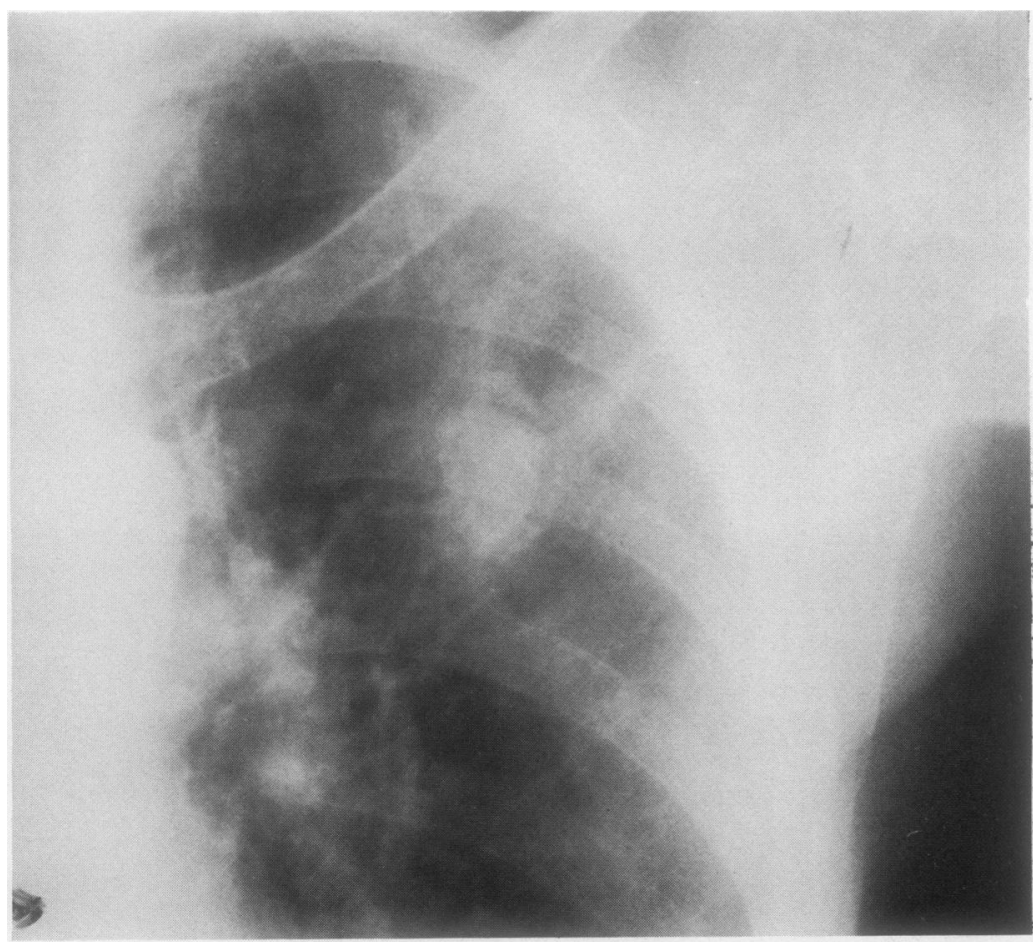

Figure 1 Radiograph of an aspergilloma in the left upper lobe showing a classical mass with an air crescent.

Aspergilloma is an opportunist infection of the lung complicating necrotic cavitary lesions

\begin{abstract}
Of 14 patients with complex aspergilloma complicating healed tuberculosis, 12 underwent lobectomy or pneumonectomy for recurrent haemoptysis. No deaths occurred, though one patient needed re-exploration for bleeding. There was no postoperative worsening of dyspnoea despite a mean forced vital capacity (FVC) of $60 \%$ predicted for the patients undergoing surgery and of $20 \%$ predicted for two patients with severe restrictive defects, perhaps owing to the fact that there was little or no function in the resected part of the lung, as shown by preoperative isotope ventilation-perfusion scanning, and that patients were under the age of 50 and generally fit. There has been no recurrence of haemoptysis during follow up, which has been from 12 to 33 months. Surgical resection, provided that cases are carefully selected, offers the best chance of cure with low mortality and morbidity.
\end{abstract} given, or had Mycobacterium tuberculosis in sputum cultures. To be eligible for inclusion all surgical patients had to have a minimum of 12 months' postoperative follow up.

\section{Results}

The 14 patients (table), eight male and six female, were aged from 16 to 50 years. Complex aspergillomas occurred in the upper lobes in 13 patients and in the lower lobes in one. Twelve patients reported recurrent moderate $(200 \mathrm{ml})$ to severe $(600 \mathrm{ml})$ haemoptysis. Preoperative spirometry showed that two patients had a normal forced vital capacity (FVC) ( $>80 \%$ predicted), seven mild abnormality (60-80\% predicted), three moderate abnormality (40-60\% predicted), and two severe abnormality ( $<40 \%$ predicted). The mean FVC for the patients undergoing surgery was $60 \%$ predicted (table).

Isotope ventilation-perfusion scans performed in 10 of the 12 patients undergoing surgery showed absent or greatly reduced perfusion and ventilation in the affected lobe or lung in all cases. Chest radiography showed an aspergilloma in eight patients; the other six aspergillomas were seen only by computed tomography. 


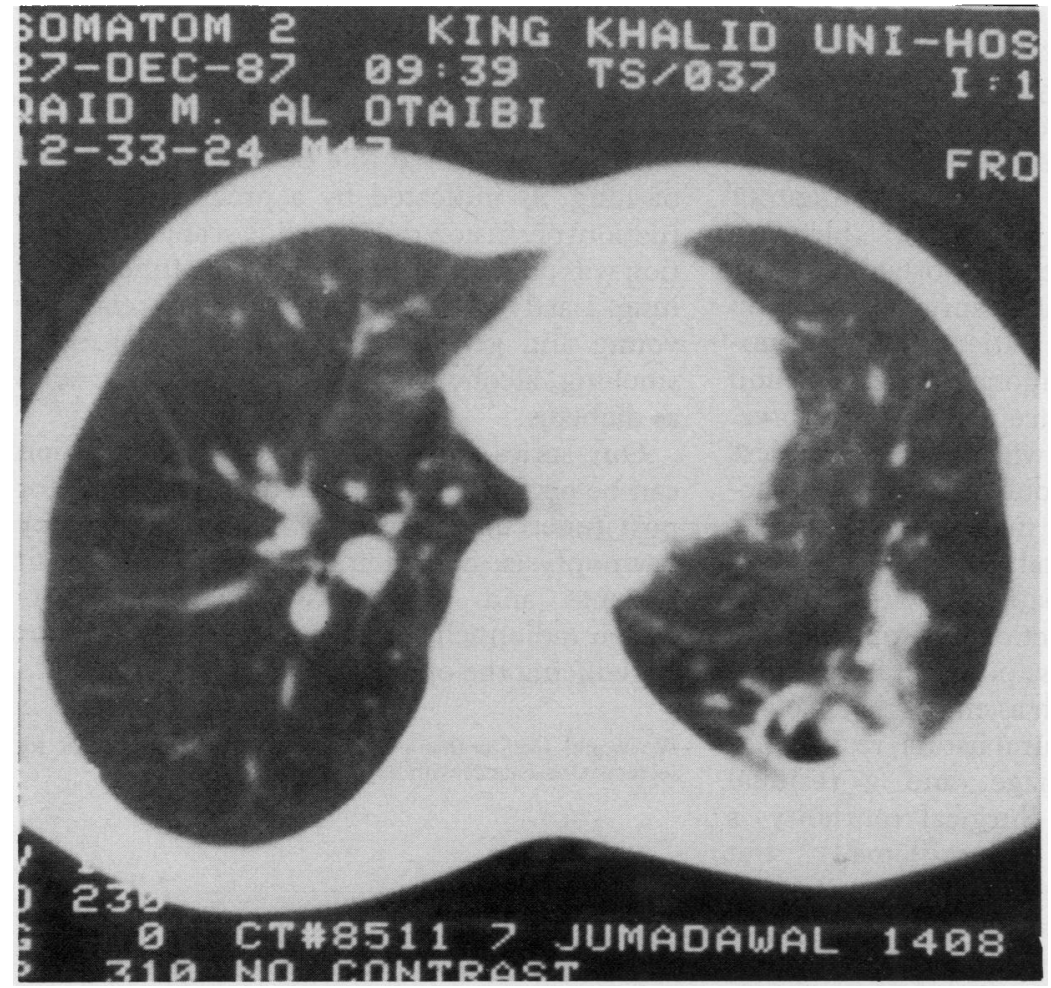

Figure 2 Computed tomogram of the chest showing an aspergilloma.

Surgical resection was performed in the 12 patients with haemoptysis. All operations were elective except in the case of patient 1 , who underwent urgent pneumonectomy for massive uncontrolled bleeding. Nine patients had a lobectomy and three a pneumonectomy. At operation dense vascular adhesions were found obliterating the pleural space and surrounding the atelectatic fibrotic lobe of the lung. Bronchial arteries were enlarged and tortuous. In two patients the aspergilloma was eroding into the chest wall. Extrapleural mobilisation was carried out in all cases. Bleeding from the chest wall responded to temporary packing with or without diathermy.

None of the surgical patients had diabetes, smoked, or were alcoholic and all could be regarded as generally fit. There was no surgical mortality and complications were low. One patient (case 5) developed transient intraoperative atrial fibrillation and another (case 8) was re-explored for postoperative bleeding. None of the patients undergoing surgery developed late complications such as empyema, bronchopleural fistula, or recurrence of aspergilloma or haemoptysis during the follow up period, which ranged from 12 to 33 months. None of the patients reported worsening of dyspnoea after resection-not even the two patients who had a severe reduction in their FVC (20\% and $37 \%$ predicted).

\section{Discussion}

Aspergilloma is an important complication of tuberculosis. In 544 patients with healed cavitary tuberculosis the prevalence of aspergilloma was $11 \%$, rising to $17 \%$ three years later. ${ }^{2}$ Although aspergillomas may undergo natural lysis and spontaneous resolution, ${ }^{24}$ most persist, giving rise to haemoptysis in more than half the patients. ${ }^{1371118}$ The high mortality from aspergilloma is frequently related to the severity of the underlying disease $e^{1318}$ rather than to the aspergilloma, and is higher in

Details of the patients

\begin{tabular}{|c|c|c|c|c|c|c|}
\hline $\begin{array}{l}\text { Case } \\
\text { No }\end{array}$ & $\begin{array}{l}\text { Age, } \\
\text { sex }\end{array}$ & Haemoptysis & Chest radiograph & $\begin{array}{l}F E V_{1}(\text { pred \%) } \\
F V C(\text { pred } \%)\end{array}$ & Ventilation-perfusion scan & Operation \\
\hline 1 & $25, \mathrm{~F}$ & Massive & $\begin{array}{l}\text { Aspergilloma left upper lobe and } \\
\text { extensive fibrotic collapse left } \\
\text { lung }\end{array}$ & $\begin{array}{ll}1.5 & (48) \\
1.9 & (46)\end{array}$ & $\begin{array}{l}\text { Substantial reduction left } \\
\text { upper zone }\end{array}$ & $\begin{array}{l}\text { Left } \\
\text { pneumonectomy }\end{array}$ \\
\hline 2 & $50, \mathrm{~F}$ & Moderate & Fibrotic collapse right upper lobe & $\begin{array}{l}1 \cdot 74(92) \\
2 \cdot 02(89)\end{array}$ & Defect right upper zone & $\begin{array}{l}\text { Right upper } \\
\text { lobectomy }\end{array}$ \\
\hline 3 & $16, M$ & Moderate & $\begin{array}{l}\text { Fibrosis collapse left upper lobe } \\
\text { and thick walled aspergilloma }\end{array}$ & $\begin{array}{ll}2 \cdot 8 & (69) \\
3 \cdot 7 & (73)\end{array}$ & Defect left upper zone & $\begin{array}{l}\text { Left upper } \\
\text { lobectomy }\end{array}$ \\
\hline 4 & 45, M & Moderate & $\begin{array}{l}\text { Fibrotic collapse left upper lobe } \\
\text { and thick walled aspergilloma }\end{array}$ & $\begin{array}{l}2 \cdot 17(70) \\
2 \cdot 97(76)\end{array}$ & $\begin{array}{l}\text { Substantial reduction left } \\
\text { upper zone }\end{array}$ & $\begin{array}{l}\text { Left upper } \\
\text { lobectomy }\end{array}$ \\
\hline 5 & $45, F$ & Moderate & $\begin{array}{l}\text { Fibrotic collapse right upper lobe } \\
\text { and thick walled aspergilloma }\end{array}$ & $\begin{array}{l}1.90(48) \\
3.06(48)\end{array}$ & $\begin{array}{l}\text { Marked reduction right upper } \\
\text { zone }\end{array}$ & $\begin{array}{r}\text { Right upper } \\
\text { lobectomy }\end{array}$ \\
\hline 6 & $30, \mathrm{~F}$ & Moderate & $\begin{array}{l}\text { Extensive fibrotic collapse left } \\
\text { lung bronchopleural fistula with } \\
\text { hydropneumothorax }\end{array}$ & $\begin{array}{ll}0 \cdot 7 & (22) \\
0.83 & (20)\end{array}$ & Defect left lung & $\begin{array}{l}\text { Left } \\
\text { pneumonectomy }\end{array}$ \\
\hline 7 & $40, M$ & Severe & Fibrotic collapse right upper lobe & $\begin{array}{l}3 \cdot 25(78) \\
4 \cdot 24(78)\end{array}$ & $\begin{array}{l}\text { Substantial reduction right } \\
\text { upper zone }\end{array}$ & $\begin{array}{l}\text { Right upper } \\
\text { lobectomy }\end{array}$ \\
\hline 8 & $47, M$ & Severe & Fibrotic collapse left lung & $\begin{array}{l}1.38(44) \\
1.42(37)\end{array}$ & Defect left lung & $\begin{array}{l}\text { Left upper } \\
\text { lobectomy }\end{array}$ \\
\hline 9 & $48, F$ & Moderate & Fibrotic collapse right upper lobe & $\begin{array}{l}1.64(69) \\
1.94(67)\end{array}$ & $\begin{array}{l}\text { Substantial reduction right } \\
\text { upper zone }\end{array}$ & $\begin{array}{l}\text { Right upper } \\
\text { lobectomy }\end{array}$ \\
\hline 10 & $50, M$ & Nil & $\begin{array}{l}\text { Fibrotic collapse left upper lobe } \\
\text { and thick walled aspergilloma }\end{array}$ & $\begin{array}{ll}1 \cdot 9 & (62) \\
2 \cdot 5 & (65)\end{array}$ & Not done & None \\
\hline 11 & $30, M$ & Nil & $\begin{array}{l}\text { Fibrosis left upper lobe and thick } \\
\text { walled aspergilloma }\end{array}$ & $\begin{array}{ll}3 \cdot 71 & (82) \\
4 \cdot 7 \quad(84)\end{array}$ & Not done & None \\
\hline 12 & $37, M$ & Moderate & $\begin{array}{l}\text { Fibrosis left upper lobe and thick } \\
\text { walled aspergilloma }\end{array}$ & $\begin{array}{l}2 \cdot 50(55) \\
3 \cdot 20(60)\end{array}$ & Not done & $\begin{array}{l}\text { Left upper } \\
\text { lobectomy }\end{array}$ \\
\hline 13 & $45, M$ & Mild & $\begin{array}{l}\text { Fibrotic collapse left upper lobe } \\
\text { and thick walled aspergilloma }\end{array}$ & $\begin{array}{l}1 \cdot 80(58) \\
2 \cdot 69(67)\end{array}$ & $\begin{array}{l}\text { Multiple matched perfusion } \\
\text { substantial in the apical part } \\
\text { of the left lung }\end{array}$ & $\begin{array}{l}\text { Left upper } \\
\text { lobectomy }\end{array}$ \\
\hline 14 & $48, F$ & Moderate & $\begin{array}{l}\text { Fibrosis and collapse } \\
\text { consolidation of apico-posterior } \\
\text { segment of right upper lobe }\end{array}$ & $\begin{array}{l}1.64(69) \\
1.94(67)\end{array}$ & Not done & $\begin{array}{r}\text { Right upper } \\
\text { lobectomy }\end{array}$ \\
\hline
\end{tabular}


patients with a diffuse lung disease such as sarcoidosis than in a localised disease such as tuberculosis. ${ }^{3}$ Haemoptysis, however, is important also as up to $28 \%$ of patients with nonmalignant aspergilloma die as a direct result of massive haemoptysis. ${ }^{19}$ The management of aspergilloma with a history of bleeding therefore acquires a special importance.

There is agreement that surgical resection should be performed in patients with haemoptysis and adequate pulmonary reserve, ${ }^{18}$ and avoided in the presence of poor reserve. Opinion is divided on whether symptomless patients should have routine surgical resection $^{7119-21}$ or be treated medically. ${ }^{14}$ There is no evidence that surgical resection improves prognosis except in patients with massive haemoptysis, ${ }^{118}$ and resection is complicated by a high rate of serious postoperative complications, ${ }^{711} 17192022$ such as empyema, prolonged air leak, bronchopleural fistula, respiratory insufficiency, haemorrhage, and a residual intrapulmonary space. Surgical mortality is below $10 \%$ in simple aspergilloma, ${ }^{1120}$ but increases to $34 \%$ in complex aspergilloma. ${ }^{17}$ Alternative procedures have been attempted in patients considered unsuitable for surgical resection but none is fully satisfactory. Treatment with intravenous amphotericin or 5flucytosine is usually ineffective. ${ }^{1318}$ Although bronchial artery embolisation arrests bleeding in most cases, haemoptysis invariably recurs, ${ }^{2324}$ possibly owing to the presence of a rich "parasite" blood supply from the chest wall to the aspergilloma. ${ }^{23}$ Endobronchial or intracavitary instillation of various antifungal agents have given encouraging results. ${ }^{1419}$ with disappearance of the mycetoma, but the long term outcome is unknown. More importantly, intracavitary instillations have resulted in serious and often fatal bleeding. Intracavitary instillation of $\mathrm{N}$-acetylcysteine and aminocaproic acid with amphotericin B was successful in arresting bleeding during acute episodes of haemoptysis, but bleeding recurred in four of the six cases. ${ }^{25}$ Radiotherapy might temporarily arrest massive haemoptysis without changing the size of the aspergilloma. ${ }^{26}$

In our series there was no recurrence of bleeding over a follow up period of 12-33 months. We encountered no serious complications or deaths despite the fact that all the patients treated surgically had complex aspergillomas and five had severe or moderate reduction in spirometric measurements. None of the patients reported worsening of dyspnoea after resection. We consider that several factors might have contributed to this favourable outcome. All our patients had unilateral disease, in which resection might be associated with a low incidence of respiratory insufficiency, though previous studies document some postoperative deaths and morbidity in post-tuberculous aspergillomas. In one study of eight cases of surgical resection for post-tuberculosis aspergilloma, one patient required postoperative tracheostomy and respiratory support and another had a prolonged air leak. ${ }^{11}$ Among nine cases of aspergilloma complicating active tuberculosis surgery resulted in two deaths from bleeding and three patients developed an empyema. ${ }^{27}$ The difference in outcome may be related to the selection of cases for surgery. Another possible factor is that resection in our patients was limited to a poorly perfused lobe or lung, as indicated by a preoperative ventilation-perfusion radionuclide scan, and attention was paid to preservation of the functioning lung. Lastly, all of our patients were relatively young and generally fit, with no history of smoking, alcoholism, or systemic disease such as diabetes.

Our series suggests that surgical resection can be performed, with relatively low risk, for post-tuberculous aspergilloma complicated by haemoptysis. Selection of relatively young, fit patients and preoperative ventilation-perfusion radionuclide scanning could play a part in reducing the operative risk.

We would like to thank Mrs Mimi S Gurrea-Villamil for secretarial assistance with this paper.

1 Jewkes J, Kay PH, Paneth M, Citron MK. Pulmonary aspergilloma: analysis of prognosis in relation to haemoptysis and survey of treatment. Thorax 1983;38:572-8.

2 Research Committee of the British Thoracic and Tuberculosis Association. Aspergillomas and residual tuberculous cavity. The result of a resurvey. Tubercle 1970;51:227-45.

3 Tomlinson JR, Sahn SA. Aspergilloma in sarcoidosis and tuberculosis. Chest 1987;92:505-8.

4 Varkey B, Rose HD. Pulmonary aspergilloma-a rational approach to treatment. Am J Med 1976;61:626-31.

5 Reddy PA. Comparison of treated and untreated pulmonary aspergilloma. Am Rev Respir Dis 1970;101:928-34.

6 Glimp RA, Bayer AS. Pulmonary aspergilloma: diagnostic and therapeutic considerations. Arch Intern Med 1983; 143:303-8.

7 Kilman JW, Ahn C, Andrews NC, Klassen K. Surgery for pulmonary aspergillosis. J Thorac Cardiovasc Surg 1969; 57:642-7.

8 Aslam PA, Eastridge CE, Hughes FA. Aspergillosis of the lung - an eighteen year experience. Chest 1971;59:28-32

9 Faulkner SL, Vernon R, Brown PP, Fisher RD, Bender $H W$. Hemoptysis and pulmonary aspergillomas: operative versus nonoperative treatment. Ann Thorac Surg 1978; 25:389-92.

10 Garvey J, Crastnopol P, Weisz D, Khan F. The surgical treatment of pulmonary aspergillosis. J Thorac Cardiovasc Surg 1977;74:542-7.

11 Solit RW, McKoewn JJ, Smullens S, Fraimow W. The surgical implication of intracavitary mycetomas (fungus balls). J Thorac Cardiovasc Surg 1971;62:411-22.

12 Belcher JR, Plummer NS. Surgery in broncho-pulmonary aspergillosis. Br J Dis Chest 1960;54:335-41.

13 Karas A, Hankins JR, Attar S, Miller JE, McLaughlin JS. Pulmonary Aspergillosis: An analysis of 41 patients. Ann Thorac Surg 1976;22:1-7.

14 Ikemoto $\mathrm{H}$. Treatment of pulmonary aspergilloma with amphotericin B. Arch Intern Med 1965;115:598-601.

15 Hargis JL, Bone RC, Stewart J, et al. Intracavitary amphotericin $B$ in the treatment of symptomatic pulmonary aspergilloms. Am J Med 1980;68:389-94.

16 Rafferty P, Biggs BA, Crompton G, Grant IW. What happens to patients with pulmonary aspergilloma? Analysis of 23 cases. Thorax 1983;38:579-83.

17 Daly RC, Pairolero PC, Piehler JM, Trastek VF, Payne WS Bernatz PE. Pulmonary aspergilloma-Results of surgical treatment. J Thorac Cardiovasc Surg 1986;92:981-8.

18 Johnson JS. Pulmonary aspergillosis. Semin Respir Med 1987;9:187-99.

19 Eastridge CE, Young JM, Cole F, Gourley R, Pate JW. Pulmonary aspergillosis. Ann Thorac Surg 1972;13: 397-403.

20 Garvey J, Crastnopol P, Weisz D, Khan F. The surgical treatment of pulmonary aspergillomas. $J$ Thorac treatment of pulmonary asper

21 Soltanzadeh H, Wychulis AR, Sadr F, Bolanowski PJ, Nenille WE. Surgical treatment of pulmonary 
aspergilloma. Ann Surg 1977;186:13-6.

22 Battaglini JW, Murray GF, Keagy PA, Starek PJK, Wilcox BR. Surgical management of symptomatic pulmonary aspergilloma. Ann Thorac Surg 1985;39:512-6.

23 Remy J, Arnaud A, Fardou H, Giraud R, Voisin C. Treatment of hemoptysis by embolization of bronchial arteries. Radiology 1977;122:33-7.

24 Uflacker R, Kaemmerer A, Neves C, Picon DP. Management of massive hemoptysis by bronchial artery embolization. Radiology 1983;146:627-34.
25 Shapiro MJ, Albelda SM, Mayock RL, McLean GK. Severe hemoptysis associated with pulmonary aspergillomapercutaneous intracavitary treatment. Chest 1988;94: 1225-31.

26 Shneerson JM, Emerson PA, Phillips RH. Radiotherapy for massive haemoptysis from an aspergilloma. Thorax 1980;35:953-4.

27 Adeyemo AD, Odelowo EO, Makanjuola DI. Management of pulmonary aspergilloma in the presence of active tuberculosis. Thorax 1984;39:862-7. 